\title{
Foreword: Vulnerability assessment in natural hazard risk-a dynamic perspective
}

\author{
Sven Fuchs ${ }^{1} \cdot$ Thomas Glade $^{2}$
}

Received: 23 February 2016/Accepted: 24 March 2016/Published online: 11 April 2016

(C) Springer Science+Business Media Dordrecht 2016

Given the conditions of global environmental change such as outlined in the fifth assessment report of the Intergovernmental Panel on Climate Change (Stocker et al. 2013), impacts from natural hazards are manifest worldwide (Field et al. 2014). Such impacts are the result of both the frequency and magnitude of the hazard and the exposure of the society or elements at risk such as buildings or transport corridors. The assessment of vulnerability is an essential part within the assessment of resulting risks (Varnes 1984). Commonly, these assessments relate purely to negative outcomes from hazard events such as the decreased stability of buildings (Holub et al. 2012) or to possibilities of communities being affected (Cutter and Finch 2008). Available studies relate in particular to natural science and engineering approaches (Glade 2003; Papathoma-Köhle et al. 2012) or approaches from the social sciences (Kasperson and Berberian 2011; Birkmann et al. 2013), but other types of vulnerability such as socio-ecological vulnerability are also inherent, yet often not covered (Fekete 2012). Similarly, the concept of resilience (again) became popular in risk assessment and needs to be explored (Alexander 2013). Both terms, vulnerability and resilience, relate among other things to coping capacities and strategies of affected people and communities, to intangible and indirect economic losses, and to communication and education networks (Birkmann et al. 2013). In addition to partially addressed aspects of vulnerability, there is neither a uniform and well-excepted technique or method or standard available to assess vulnerability within its multifaceted nature. Similarly, different approaches of resilience often remain in their disciplinary corner and comprehensive approaches are rare. In addition, underlying causes and forces determining

Thomas Glade

thomas.glade@univie.ac.at

Sven Fuchs

sven.fuchs@boku.ac.at

1 Institute of Mountain Risk Engineering, University of Natural Resources and Life Sciences, Vienna, Austria

2 Institute of Geography and Regional Research, University of Vienna, Vienna, Austria 
both vulnerability and resilience do change in time and space. Therefore, both concepts have to address the inherent dynamics of these changes as well. Such dynamics might be caused by natural variations such as climatic changes, but might also be determined by socio-economic transformations such us urban spread or infrastructure construction. And indeed, these changes often happen to different degrees simultaneously, a situation which is challenging for all affected parties.

This Special Issue is based on contributions of session NH9.7 at the EGU General Assembly 2013 held in Vienna, Austria, 07-12 April 2013, and some additionally invited contributions. The volume presents some recent studies to summarize the assessment of different types of vulnerabilities (e.g. social, personal, structural, economic, political, environmental) and resilience for different natural hazard phenomena. The main focus herein is to show different strategies based on developments from different disciplines and to discuss these according to similarities, but also differences. Taking the findings and results of two Special Issues that were recently published in Natural Hazards (Fuchs et al. 2011, 2012) as starting point, this Special Issue contributes with interdisciplinary articles that summarize the concepts of vulnerability and resilience by using regional case studies and findings from European research projects and beyond.

Greco and Martino discuss the requirements of the EU Floods Directive (Commission of the European Communities 2007) for coastal hazards in Southern Italy with a particular focus on the challenges associated with vulnerability assessment. Using a Coastal Criticality Index as a combination from flood and erosion hazard, they propose a procedure to support vulnerability, risk, and resilience mapping facing the development of risk management plans. Morphologic and socio-economic variables have been used to evaluate a Coastal Erosion Index. Furthermore, a set of indices and indicators representing hazard, vulnerability, and exposure have been used to estimate the Coastal Flood Index (CFI). Combining these indices, the authors have shown how a regional analysis of vulnerability can be performed to support the implementation of the EU Flood Directive for coastal areas.

Michellier et al. show in their contribution how vulnerability assessment can be contextualized with respect to geohazards in Central Africa. Geohazards include processes of seismic and volcanic origin as well as mass movements. Referring to the Hyogo Framework for Action priority 3, 'use knowledge, education and innovation to build a culture of safety and resilience at all levels' (United Nations Office for Disaster Risk ReductionUNISDR 2007), the authors discuss an attempt to integrate the spatial analyses of past and present multiple geohazards occurring in the region, and vulnerable elements such as local population, buildings, and networks that are threaten. Involving local knowledge and capacities together with available data, the authors show how a dynamic assessment approach may be used for decision-making and adaptation in a local context in order to enhance resilience and reduce vulnerability.

Zemtsov et al. present an integrated and regional assessment of socio-economic vulnerability to flood hazards in parts of the Krasnodar region at the Black Sea, Russian Federation. They show how not only direct and tangible assets can be operationally assessed, but also social vulnerability can be contextualized, such as human life and health. The study allowed the authors to identify the specific challenges with respect to the preparedness for defined flood hazard scenarios in the Slavyansk municipal district. Moreover, the results clearly revealed the importance of both social and economic components of vulnerability assessment in order to improve the current procedure of risk assessment in the Russian Federation (EMERCOM 2011). 
Karagiorgos et al. report on a regional study undertaken in Greece and focusing on a multi-vulnerability assessment for flash flood hazards. By analysing both physical and social vulnerability, an attempt was made to bridge the gap between scholars from sciences and humanities and to integrate the results of the analysis into the broader vulnerability context. The empirical research presented in this paper stresses that there are several factors as well as interactions shape vulnerability in a dynamic concept (Fuchs 2009), such as the integration of vulnerability components, the integration of methods, and the target dimension of vulnerability assessment. The authors conclude that even in case of extreme events, the vulnerability of the (social) system to stress is considerably low due to social networks, economic settings as well as institutional and political factors, and consequently the speed of return to the equilibrium steady state, defined as the prevailing livelihood conditions, is fast.

Papathoma-Köhle et al. present a regional study on the vulnerability to heat waves in the Arad region, Western Romania. Facing the challenge of data scarcity, their study made no use of population characteristics and their location, but illustrated vulnerability as the impact of the hazard to the population expressed as an index depending on the number of medical interventions at the neighbourhood level. The resulting maps difference in the risk rate of districts experiencing a similar level of hazard exposure. The authors clearly show the effects of socio-economic differences and highlight the role of vulnerability within risk assessment pointing out the need for detailed data regarding the population and its vulnerability to extreme temperatures.

Promper and Glade report on multilayer exposure mapping as a basis for regional vulnerability assessment for landslides in Austria. They show the landslide exposure of different elements at risk in one map, e.g. residential buildings and critical infrastructure, as a basis for a further analysis of vulnerability and risk. The results show different levels of exposure, as well as how many layers of elements at risk are affected. Several vulnerability hot spots can be delineated throughout the study area, and the approach presented enables to overcome the data intensive assessments on a regional scale and highlights the potential hot spots for cost-efficient risk analysis.

Taking a wider viewpoint and using a theoretical narrative, Kelman et al. describe the importance of existing vulnerability and resilience studies for contemporary investigations involving climate change by suggesting ways forward independently from disciplinary constraints. In their contribution, vulnerability and resilience are explored as processes alongside critiques of the post-disaster 'return to normal' paradigm. The importance of learning from the already existing literature and experience is demonstrated for ensuring that complete vulnerability and resilience processes are accounted for by placing climate change within other contemporary development concerns.

The assessment of spatial dimensions is an essential part within integrated disaster risk management; however, this has so far often been neglected in respective academic efforts (Müller-Mahn 2013). Understanding the spatial patterns of vulnerability, as well as the geographical limits of their trigger, and the development of appropriate management strategies is crucial in disaster risk management, both risk reduction measures prior to an event and response and recovery efforts (Aubrecht et al. 2013). While patterns of exposure are basically evolving on all spatial scales and are often subjected to short-term and longterm dynamics, changes in vulnerability usually rather occur on a longer term such as changes in regional population or economic characteristics. Therefore, vulnerability is critically context dependent (Brooks et al. 2005), and variable patterns of vulnerability determine where and when a mere natural event potentially turns into a disaster. 
The Special Issue provides some insights into these issues and has a particular focus on different methods to determine vulnerability and resilience on a regional scale-and as such independent from the often-published large-scale case studies where a further application of the respective method to other case studies is challenging due to the specific data requirements. The guest-editors would like to foster a scientific discussion on such approaches in order to further stimulate the discussion on vulnerability and resilience in natural hazard management.

Acknowledgments We would like to express our sincere thanks to the management and Editorial Board of Natural Hazards, above all Tad Murty who served as the Coordinating Editor, as well as Petra van Steenbergen, Stefan van Dijl, Sridhar Bhavani and the entire of the team from the Editorial Office of Springer. Moreover, we would like to acknowledge the efforts of all the reviewers who supported this Special Issue with their knowledge on different aspects of vulnerability and resilience in natural hazard risk management and their constructive criticism that helped us and the authors to further develop the individual argumentations in the papers. We would also like to thank all the colleagues who contributed to this Special Issue, above all for their patience during the process of manuscript production and revision.

\section{References}

Alexander D (2013) Resilience and disaster risk reduction: an etymological journey. Nat Hazards Earth Syst Sci 13(11):2707-2716

Aubrecht C, Fuchs S, Neuhold C (2013) Spatio-temporal aspects and dimensions in integrated disaster risk management. Nat Hazards 68(3):1205-1216

Birkmann J, Cardona OM, Carreño ML, Barbat AH, Pelling M, Schneiderbauer S, Kienberger S, Keiler M, Alexander D, Zeil P, Welle T (2013) Framing vulnerability, risk and societal responses: the MOVE framework. Nat Hazards 67(2):193-211

Brooks N, Adger WN, Kelly PM (2005) The determinants of vulnerability and adaptive capacity at the national level and the implications for adaptation. Glob Environ Change A 15(2):151-163

Commission of the European Communities (2007) Directive 2007/60/EC of the European Parliament and of the Council of 23 October 2007 on the assessment and management of flood risks. Off J Eur Union L 288:27-34

Cutter S, Finch C (2008) Temporal and spatial changes in social vulnerability to natural hazards. Proc Natl Acad Sci USA 105(7):2301-2306

EMERCOM (ed) (2011) Guidelines for the organization and implementation of activities aimed at reducing the effects of spring floods and floods [in Russian: Методические рекомендации по организации и проведении мероприятий, направленных на снижение последствий весеннего половодья и павод, ков]. EMERCOM, Moscow

Fekete A (2012) Spatial disaster vulnerability and risk assessments: challenges in their quality and acceptance. Nat Hazards 61(3):1161-1178

Field CB, Barros VR, Dokken DJ, Mach KJ, Mastrandrea MD, Bilir TE, Chatterjee M, Ebi KL, Estrada YO, Genova RC, Girma B, Kissel ES, Levy AN, MacCracken S, Mastrandrea PR, White LL (eds) (2014) Climate Change 2014: impacts, adaptation, and vulnerability. Cambridge University Press, Cambridge

Fuchs S (2009) Susceptibility versus resilience to mountain hazards in Austria: paradigms of vulnerability revisited. Nat Hazards Earth Syst Sci 9(2):337-352

Fuchs S, Kuhlicke C, Meyer V (2011) Editorial for the special issue: vulnerability to natural hazards: the challenge of integration. Nat Hazards 58(2):609-619

Fuchs S, Birkmann J, Glade T (2012) Vulnerability assessment in natural hazard and risk analysis: current approaches and future challenges. Nat Hazards 64(3):1969-1975

Glade T (2003) Vulnerability assessment in landslide risk analysis. Erde 134(2):123-146

Holub M, Suda J, Fuchs S (2012) Mountain hazards: reducing vulnerability by adapted building design. Environ Earth Sci 66(7):1853-1870

Kasperson RE, Berberian M (eds) (2011) Integrating science and policy: vulnerability and resilience in global environmental change. Earthscan, London

Müller-Mahn D (ed) (2013) The spatial dimension of risk. Routledge, London

Papathoma-Köhle M, Keiler M, Totschnig R, Glade T (2012) Improvement of vulnerability curves using data from extreme events: a debris flow event in South Tyrol. Nat Hazards 64(3):2083-2105 
Stocker TF, Qin D, Plattner G-K, Tignor M, Allen SK, Boschung J, Nauels A, Xia Y, Bex V, Midgley PM (eds) (2013) Climate change 2013: the physical science basis: contribution of working group I to the fifth assessment report of the intergovernmental panel on climate Change. Cambridge University Press, Cambridge

United Nations Office for Disaster Risk Reduction (UNISDR) (2007) Hyogo framework for action 2005-2015: building the resilience of nations and communities to disasters. United Nations, Geneva Varnes D (1984) Landslide hazard zonation: a review of principles and practice. UNESCO, Paris 